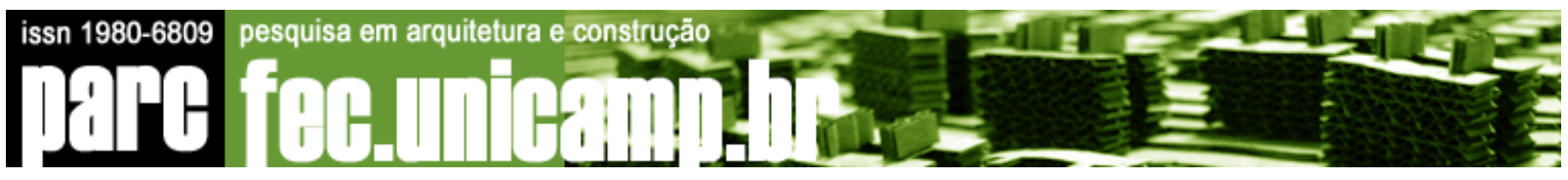

\title{
O Projeto Eixo Tamanduatehy e o alcance dos planos urbanísticos municipais
}

The Tamanduatehy Axle Project and the capacity of local urban planning

\section{ENIO MORO JUNIOR}

Arquiteto e Urbanista, graduado pela Faculdade de Arquitetura e Urbanismo da Universidade de São Paulo, Mestre e Doutor em Planejamento Urbano pela mesma instituição. Professor do Centro Universitário Belas Artes, Pesquisador do Centro Universitário Fundação Santo André e Coordenador Geral do iURB - Instituto de Estudos Urbanos do Grande ABC .

eniomorojunior@ig.com.br

\section{Resumo}

O vale do rio Tamanduateí, Santo André, SP, foi um dos principais vetores de implantação da atividade industrial brasileira do século passado. A partir da década de 1980 enfrentou profunda transformação promovida pelo Estado brasileiro, que incentivou a industrialização em outras regiões do estado e do país. Depois incentivou a internacionalização da produção e inovações gerenciais pela globalização. Estas políticas representaram para Santo André a diminuição do seu parque produtivo e a redução do emprego industrial. Como alternativa o município lança o Projeto Eixo Tamanduatehy, plano urbanístico que objetivou a reconversão econômica com sustentabilidade social.

Palavras-chave: Neoliberalismo, Poder local, Planejamento Urbano, Parcerias públicoprivada;

\section{Abstract}

The Tamanduateí Valley, Santo André, SP, Brazil, was one of the main vectors of implantation and development of the Brazilian industrial activity of the last century. From 1980's, the Brazilian Government promoted a deep transformation of the development pattern that changed the industrial activities for the other regions of the state and the country. After, promoted the implementation of new technologies and models of industrial management by 


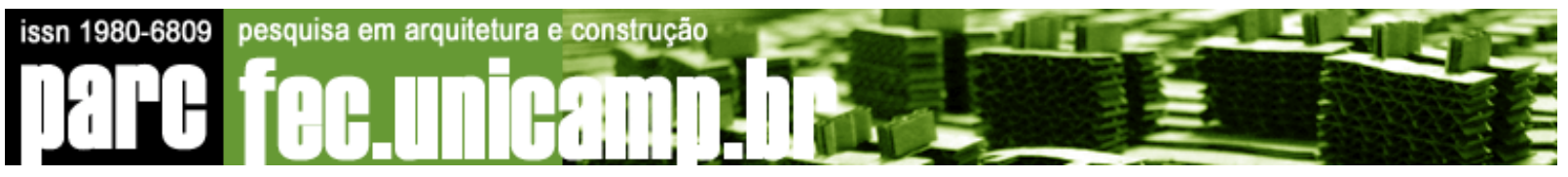

the globalization. These polices had represented for Santo André, the reduction of productive park and the industrial job. As alternative, the municipality developed the Tamanduatehy Axle Project, urban planning that objectives the economics and social improvement.

Key-words: Spatial policy, Neo-liberalism, Local power, Urban planning, Public/Private partnership;

\section{O Projeto Eixo Tamanduatehy e o alcance dos planos urbanísticos municipais}

As relações entre o crescimento da urbanização e a evolução da sociedade capitalista comprovam que os interesses contraditórios das forças produtivas apresentam expressa manifestação na produção do espaço. O papel do Estado, meio e fim da hegemonia da classe dominante, garante por meio da promoção e monitoramento do desenvolvimento urbano as condições materiais para a reprodução das relações capitalistas. Suas ações na implantação de infra-estrutura física afirmam a sobreposição de interesses pela classe que o domina sob a primazia da unificação do mercado e a relação de poder entre classes e sua expressão espacial apresentam particularidades no caso brasileiro.

Enquanto o capitalismo europeu e norte-americano consolida, a partir do século XIX, relações entre a burguesia e o proletariado, nossa classe dominante aprofunda a importação de bens manufaturados e exporta produtos tropicais produzidos pela mão-de-obra escrava associados ao capital estrangeiro, contrapondo-se a uma industrialização autônoma. O modelo brasileiro não gerou uma classe dominante como a burguesia européia ou norte-americana e sim uma sociedade de elite que preserva suas bases internas e relações de poder inibindo 0 desenvolvimento desimpedido do capitalismo interno (SCHIFFER, 1989).

Este modelo expatriador, que também atende as necessidades de reprodução do capitalismo internacional, impede o pleno desenvolvimento das forças produtivas pois uma parte do excedente não é reincorporada à reprodução ampliada interna. Este processo, chamado de acumulação entravada (DEÁK, 1989), assegura a hegemonia da elite nacional restringindo o mercado interno às demandas de sua autopreservação e esta contínua reimposição perpetua o subdesenvolvimento brasileiro. A ruptura desta dinâmica e a negação desta condição de 
subdesenvolvimento crônico são impedidas pelas estratégias de dominação da elite em suas dimensões econômica, jurídica, institucional e ideológica.

O rápido e intenso processo de urbanização brasileiro revela na lógica da manifestação espacial da acumulação entravada o desequilíbrio entre espaços plenamente servidos de infra-estrutura com a omissão do Estado em áreas profundamente precarizadas. Nossa sociedade de elite não necessita elevar o nível de subsistência do trabalhador justificando a imposição de mínimas condições para a reprodução da força de trabalho e prioriza a produção do espaço para suas conveniências, como sistema viário, transportes ou oportunidades para o mercado imobiliário. Esta dinâmica secular de produção do espaço reinventa-se na recente "globalização" brasileira em um novo arranjo para manutenção da acumulação entravada transferindo ao mercado setores controlados pelo Estado.

As premissas para a compreensão deste processo remetem-nos ao colapso do Estado Keynesiano da década de 1970, que no Brasil traduziu-se pelo desmonte da política desenvolvimentista adotada a partir de meados do século passado e o comprometimento de seu arremedo de rede de proteção social. O financiamento do Estado desenvolvimentista sofreu um de seus principais reveses na alteração das taxas fixas para taxas flutuantes referentes ao pagamento do principal e do serviço da dívida externa brasileira durante as décadas de 1970 e 1980. Este rompimento de padrão promoveu uma intensa transferência de reservas cambiais e de recursos das exportações brasileiras para a recomposição das reservas internas dos credores internacionais.

O prosseguimento possível do financiamento do Estado desenvolvimentista deu-se principalmente pela emissão de moeda e captação de recursos no mercado interno através do oferecimento de altas taxas de juros. Este expediente, negação de um projeto macroeconômico de desenvolvimento do capitalismo interno que sinalizasse para o rompimento dos interesses dominantes, foi um dos responsáveis pelo profundo processo inflacionário do período definindo a política econômica a partir dos recursos disponíveis para o pagamento da dívida externa.

As diretrizes apontadas no emblemático Consenso de Washington, de 1989, condicionaram a cooperação financeira internacional à desregulação do mercado financeiro e do trabalho, privatização de estatais e serviços públicos, abertura comercial e controle da inflação a qualquer preço, seja este o aprofundamento do achatamento salarial ou o comprometimento definitivo do desenvolvimentismo (BATISTA, 1994). A partir de um discurso sedutor em nome 
da "modernidade administrativa" ou da "ineficiência" da atuação do Estado, este choque liberal, alcunhado de neoliberalismo, garantiu a preservação da elite e seu modelo expatriador associado ao capital internacional em bases bem menos favoráveis no mercado interno tanto por meio da diminuição do Estado e do capital privado nacional como também pela significativa ampliação do capital estrangeiro (GORENDER, 2000).

A adoção das políticas neoliberais produziu resultados medíocres para o desenvolvimento social com o aprofundamento da concentração de renda, a cristalização de uma casta de miseráveis e níveis de tensão social, desemprego e criminalidade nunca observados.

O urbanismo neoliberal aderiu aos "novos conceitos" que incorporam a lógica privada na agenda pública por meio do instigante desafio de capacitar a cidade de forma artificial e cenográfica à plena reprodução do capital ou ainda à "cidade global". Os administradores públicos da década de 1990 concentraram investimentos públicos em áreas de interesse do capital privado e procuraram ocultar o rebatimento espacial do conflito de classes. $O$ "paradigma da modernidade" seria a abertura de espaços para o mercado, o dinamismo econômico como pré-condição para a qualidade de vida e investimentos em segurança, consumo e cultura como atrativos para novos empreendimentos econômicos. A capacidade de gerar riquezas e estabelecer competências para a produção de bens e serviços mediu o desempenho dos prefeitos.

A Constituição Federal de 1988 e o neoliberalismo da década de 1990 garantiram um parcial aumento de autonomia aos municípios e reforçaram a ilusão do protagonismo municipal na resolução de questões estruturais e conjunturais brasileiras. $\mathrm{O}$ discurso municipalista, entre outras mazelas, se apropriara de termos oriundos da livre tradução dos manuais técnicos das agências internacionais de fomento, como por exemplo, "poder local", "atores" ou "planejamento estratégico". O contraponto ao enfraquecimento do Estado ou ainda à face possível do Estado "mínimo" foi a valorização do voluntarismo municipal equivocado cujo alcance, em um contexto de acumulação entravada restringiu-se, por origem, nas limitações do arranjo federativo e alguns de seus desdobramentos, como por exemplo a guerra fiscal, a lei de responsabilidade fiscal ou o Estatuto da Cidade.

Apesar de representar um importante instrumento público municipal para gestão e intervenção na propriedade privada, a atuação do Estatuto da Cidade (EC) é muito limitada por contrapor-se aos interesses dominantes. Dentre os instrumentos previstos, as Operações Urbanas Consorciadas e suas "inquestionáveis" parcerias possuem aparente lógica e 
discurso da acumulação desimpedida mas com práxis e resultados de um contexto de acumulação entravada. Sucintamente intencionavam prover infra-estrutura pública através da iniciativa privada em troca de normatização de liberalidades no mercado imobiliário. As Operações Interligadas permitiram intervenções pontuais em algumas áreas de interesse do mercado imobiliário sem considerar os impactos que estas intervenções poderiam ter na infra-estrutura já instalada, fato que gerará grandes investimentos públicos para sanar as novas demandas. As Operações Urbanas, parcerias público-privadas em perímetros determinados pela dinâmica imobiliária, expandiram a possibilidade de alteração de zoneamento por meio da venda de potencial construtivo acima do permitido em seu perímetro viabilizando assim o financiamento das obras e serviços previstos ou ainda a transferência deste potencial para outras áreas da cidade. Estas parcerias podem viabilizar expressas alterações de zoneamento sem o demorado trâmite legislativo e ainda gerar recursos extraorçamentários de difícil fiscalização. O contraponto é que o poder público absorve o impacto gerado pelo futuro adensamento e é conivente com o aprofundamento das diferenças intraurbanas.

A viabilidade das parcerias só ocorre em áreas de interesse do mercado imobiliário e com a realização de investimentos públicos preliminares para consolidação das perspectivas de valorização. A iniciativa privada nunca perde (FIX, 2001). O principal mote dos defensores destas parcerias seria seu autofinanciamento, ou seja, o capital privado viabiliza 0 investimento na reordenação de grandes áreas "liberando" o poder público para investimentos em áreas carentes, discurso que sensibilizou governos progressistas e conservadores de todo o Brasil.

Estes instrumentos técnicos disponíveis para a atuação urbana do poder municipal não se contrapõe aos interesses dominantes. A resignação do poder municipal "progressista" é atuar na minimização das conseqüências da acumulação entravada, como reurbanização de favelas ou bolsas assistencialistas, e não intervir em suas causas. Esta dinâmica é favorável a manutenção do "status quo" e desvia-se do nexo central da discussão, a questão das classes no Brasil.

Ainda neste sentido, o modelo de convergência de renda e riqueza em poucas áreas geográficas representado pela concentração regional da industrialização brasileira no estado de São Paulo até meados dos anos 1970, as desigualdades econômicas e espaciais da distribuição da população brasileira ou ainda a manutenção das mínimas condições para 


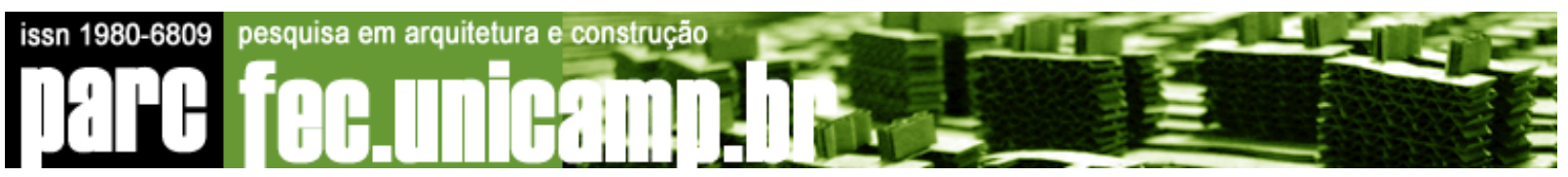

reprodução da força de trabalho são dimensões do modelo do desenvolvimento capitalista brasileiro.

O desmonte do desenvolvimentismo contraposto pelo II PND - Plano Nacional de Desenvolvimento - de 1974 considerou a metrópole paulista como área de descompressão ou contenção e passível de esforços para evitar seu o crescimento excessivo (EMPLASA, 1994). Neste contexto, a atuação do Estado na desconcentração industrial da Região Metropolitana de São Paulo foi extremamente eficiente aliando desde incentivos à instalação de novos empreendimentos no interior do estado à obstáculos legais para expansão da atividade industrial ou implantação de infra-estrutura regional. O ápice deste movimento descentralizador fora em meados de 1980 por meio da lei de localização e proteção ambiental do estado de São Paulo e a proposta de atualização e ajuste na lei de desenvolvimento e zoneamento industrial.

Este conjunto de ações promovidas pelo Estado brasileiro, que alterou o mapa de desenvolvimento econômico do maior parque industrial do hemisfério sul, em nada representou na melhoria das condições de reprodução da força de trabalho.

A dinâmica da instalação do capital industrial na sub-região sudeste da Região Metropolitana de São Paulo, conhecida como Grande $A B C$, caracterizou a região como principal pólo industrial e operário da América do Sul, foi profundamente impactada pois além das restrições discutidas, cerca de $56 \%$ do seu território localiza-se em Área de Proteção de Mananciais, com severas restrições ambientais e, portanto altamente restritivo para a implantação da atividade industrial.

O município de Santo André apresentava no período entre 1920 e 1990 excelentes vantagens locacionais para a implantação e desenvolvimento da atividade industrial: existência de grandes áreas livres, ligação ferroviária com o Porto de Santos, um dos principais portos de importação e exportação da América Latina, energia elétrica abundante, proximidade com os mercados de São Paulo, mão-de-obra qualificada e ainda a continuidade física da expansão industrial do município de São Paulo. O vale do rio Tamanduateí, que além de Santo André atravessa também os municípios de Mauá, São Caetano do Sul e São Paulo, é o local de estabelecimento destas atividades industriais.

A desconcentração industrial deixou para o município grandes galpões industriais subutilizados em áreas plenamente servidas de infra-estrutura, queda do nível e qualidade de 
emprego e expansão das áreas favelizadas, principalmente nas áreas de proteção de mananciais, protegidas contra a expansão industrial mas não fiscalizadas contra as ocupações clandestinas.

Já a reestruturação produtiva e a adoção das políticas neoliberais na década de 1990, como a abertura às importações e novos ditames da competitividade do mercado global produziu na base industrial de Santo André um significativo aumento da produtividade nas indústrias remanescentes, que passaram a produzir mais com menos mão-de-obra mantendo a competitividade industrial do Grande ABC. Ainda neste período diversos segmentos do setor industrial implementaram ajustes e reestruturações que incluíram sinteticamente a redução de níveis administrativos e hierárquicos e a adoção de novos processos e técnicas de produção. Este processo, muito mais próximo de uma transformação do tecido industrial que a propalada evasão industrial, é o novo paradigma para o aprofundamento do processo de acumulação.

A diminuição do peso relativo da atividade industrial não significou uma expansão do setor terciário qualificado, como por exemplo, o comando empresarial, planejamento de novos produtos ou gestão financeira e sim um aumento no número de empregos setoriais de baixa qualificação em comércio e serviços. As deseconomias geradas pelas conseqüências do esvaziamento industrial implicam para o poder público municipal no aprofundamento da demanda habitacional para baixa renda, infra-estrutura urbana, saneamento, drenagem, saúde, educação e ainda pelos altos índices de desemprego e violência urbana. O Brasil neoliberal não apontou para a criação de um mercado de massas ou ainda da ampliação do mercado de consumo brasileiro, reforçando as características da acumulação entravada. No Grande ABC, os administradores públicos e os agentes sociais e econômicos enfrentam quixotescamente o desafio de buscar alternativas para diminuir as conseqüências deste modelo perverso e não enfrentar suas verdadeiras causas.

A desconcentração industrial e a reestruturação produtiva transformaram o perfil da produção do espaço no vale do rio Tamanduateí. A tentativa de reversão deste processo foi induzida pela Prefeitura Municipal de Santo André por meio da criação de um projeto de requalificação urbana que conduzisse à reconversão econômica do município. A proposta do "Projeto Eixo Tamanduatehy" (PET), lançado oficialmente em 1997 previa a implantação de novos empreendimentos econômicos, culturais e sociais por meio de ações integradas entre o poder público municipal, a comunidade, a iniciativa privada e as instituições representativas 
da sociedade civil, sugerindo a inexistência de conflitos e a convergência de interesses. Esta diretriz baseou-se no conjunto de ações e políticas públicas implantadas em Barcelona entre 1983 e 1995, período que Jordi Borja, um dos consultores contratados pela municipalidade de Santo André, ocupou cargos diretivos na Prefeitura de Barcelona.

Esta tentativa de transposição de diagnósticos idênticos entre realidades distintas norteou 0 ideário urbanístico de concepção do PET, trazendo à pauta do Grande $A B C$ uma série de "novidades" como as redes de cidades, as parcerias público-privadas, o planejamento estratégico, o city marketing e enfim a ilusão do protagonismo do município na resolução de problemas econômicos e sociais. A administração municipal contratou quatro estudos urbanísticos sendo 3 coordenados por arquitetos europeus (Joan Busquets, Eduardo Leira e Christian de Portzamparc) consorciados com equipes brasileiras, e a equipe brasileira coordenada pelo arquiteto e urbanista Cândido Malta Campos Filho . Os produtos gerados, de grande qualidade de desenho urbano, previam, entre outras propostas, a potencialização do posicionamento metropolitano do vale do rio Tamanduateí como pólo indutor para desenvolvimento econômico das zonas leste e sudeste da Região Metropolitana da Grande São Paulo, melhor articulação física com aeroportos e porto de Santos, valorização do transporte ferroviário para cargas e passageiros, novo arranjo fundiário, marcos referenciais, edifícios emblemáticos, centros culturais, áreas verdes, incentivo ao uso coletivo intenso, à mistura de classes sociais, à estimulação de novas atividades econômicas, de lazer e moradia.

Os valores para implantação de qualquer um desses projetos, em 2001, seriam de aproximadamente 1,2 bilhões de reais, praticamente o quádruplo da receita orçamentária anual total do período, conforme apuração do Departamento de Projetos Urbanos da Prefeitura Municipal de Santo André (DPU/PMSA). Com este distante horizonte a equipe técnica do PET desenvolveu um projeto-síntese que propunha uma profunda revisão do sistema viário, um relacionamento diferenciado entre a via férrea, o rio Tamanduateí e a av. dos Estados e o entorno além de novos empreendimentos públicos e privados distribuídos estrategicamente pelo vale para induzir o movimento de renovação urbana pelo mercado imobiliário. Esta revisão incorporou as parcerias previamente em andamento, como Cyrella, Pirelli e Funcef.

O projeto-síntese também não contemplou ações urbanas para as fragilidades municipais em habitação, saneamento, drenagem e transportes e logo no início de 2002, uma revisão crítica 
realizada pela nova equipe do PET desmontou algumas expectativas como a ilusão do "terciário avançado", discurso corrente numa região que impera a indústria pesada reprodutora de tecnologia internacional ou a presunção de uma nova "centralidade regional", que está muito mais próxima de um modelo idealizado que seu alcance e possibilidades. $\mathrm{O}$ mote desta revisão foi o conceito de urbanismo "includente e participativo", ou seja, requalificação urbana por meio de transferência de valores materiais, como propriedade e renda, e valores simbólicos, como o direito à cidade, gestão participativa e eqüidade social. Este discurso limitou-se não só nas visões díspares internas de segmentos da administração como também pela difícil viabilização da participação popular, seja pelo desinteresse em implantar um grupo gestor ou ainda pela desilusão popular pelo distanciamento entre demandas prementes apontadas nas reuniões do Orçamento Participativo e os recursos gerados nas contrapartidas.

A implantação, mesmo para a proposta mais modesta que se delineara nesta revisão, necessitaria de recursos extramunicipais tanto de fontes privadas como de públicas. Esta revisão também aproximou a desmistificação do protagonismo municipal tanto na geração de trabalho e renda, demonstrando que salvo algumas limitadas vantagens fiscais, pouco o município poderia fazer na manutenção e atração de atividades produtivas. A provisão habitacional, os transportes e a infra-estrutura física são ações que traduzem uma política de Estado e o município pouco pode atuar.

A pecha de uma alardeada política urbana alternativa foi um precioso equívoco que além de distanciar ainda mais o debate político sobre a ruptura necessária da acumulação entravada, anacronicamente manifestava-se nos conflitos e entraves da legislação urbana, aparato institucional e na captação e gestão de recursos. Sobre a fragmentação da legislação urbanística a incompatibilidade usos e índices de municípios lindeiros e conurbados dificultavam o necessário enfoque regionalizado. Especificamente em Santo André, a legislação urbana é formada por um rol de inúmeros decretos e leis desvinculado da melhoria da qualidade na apropriação dos espaços.

A regulamentação de situações irregulares extremamente específicas ocorria por meio de usos e índices urbanísticos autorizados mediante outorga onerosa, chegando ao ponto de lotes possuírem índices específicos e distintos de seu entorno. Nesta mesma linha foi aprovada entre 2000 e 2002 um conjunto de leis urbanas que autorizava atividades industriais, comerciais, prestação de serviços ou de habitação de interesse social em todo o 
território do município mediante avaliação do empreendimento e respectiva aprovação da outorga onerosa. Os conflitos cotidianos entre as legislações municipal, estadual e federal se expressavam tanto no embate entre o restritivo zoneamento industrial da Região Metropolitana, que compreende $75 \%$ da área do PET e a permissiva legislação municipal como também na regularização cartorial de permutas ou doação de áreas entre o poder público e a iniciativa privada, penoso ritual que enquanto inconcluso impedia a adequada cobrança do IPTU ou ainda a plena utilização da área remanescente.

Além dos obstáculos legais e institucionais, a captação e gestão de recursos também apresentavam suas particularidades pois nunca existiu uma fonte permanente de recursos ou dotação orçamentária específica. O PET utilizava esporádicos recursos públicos e privados. Os investimentos públicos diretos concentraram-se na precária recuperação da infra-estrutura viária, contenções do rio Tamanduateí, micro-drenagem, iluminação pública e recuperação de praças e jardins; além disso o Programa Habitar Brasil/CEF destinou recursos da ordem de 3 milhões de dólares para recuperação de um conjunto de áreas favelizadas no município.

A principal fonte de recursos era a outorga onerosa das alterações pontuais de usos e índices da legislação urbana vigente desde o apogeu industrial. Estas alterações atendiam a um emergente mercado imobiliário para implantação de atividades de comércio ou serviços e tornava evidente a cumplicidade do poder público municipal neste mercado sem utilizar instrumentos públicos para captação da valorização imobiliária. Outro ponto frágil era a valoração das contrapartidas e a destinação dos recursos gerados pela outorga onerosa. Não existia metodologia única adotada para apuração dos valores de contrapartida tampouco prazos de duração das liberalidades urbanísticas ou para a execução das contrapartidas pelos empreendedores. Mesmo assim e apesar da irregularidade no ingresso dos recursos, a partir de 1998 esta fonte auxiliar representou, em valores aproximados, cerca de 2,5\% da receita orçamentária total.

As inconsistências na gestão e destinação dos recursos gerados são os pontos mais dispares. Os recursos privados investidos nos novos empreendimentos é superior aos valores das contrapartidas investidas na coisa pública, que mal chegavam a $7 \%$ do valor total do empreendimento, conforme o DPU/PMSA. A comparação entre os recursos gerados e sua destinação específica demonstra que significativa parcela destes recursos $(97,5 \%)$ foi reinvestida na própria viabilização do empreendimento, reproduzindo o modus operandi clássico das Operações Urbanas do Brasil neoliberal. Não existiu uma política municipal 


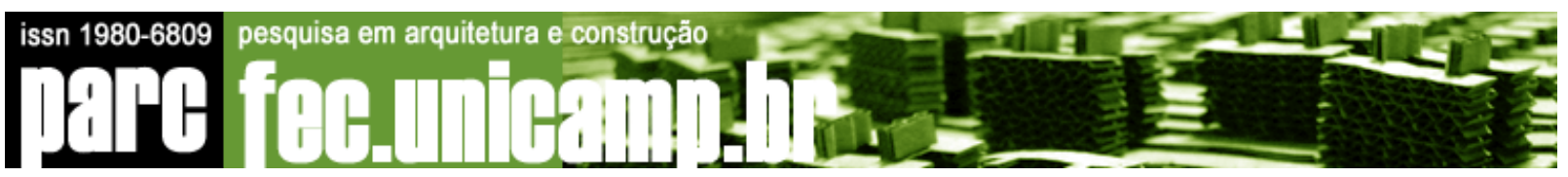

específica sobre a destinação social de pelo menos parte dos recursos gerados nas contrapartidas. Este desequilíbrio traduzia um conflito básico da dinâmica das parcerias entre o poder público e a iniciativa privada: a transferência de recursos privados para as ações públicas é profundamente articulada à própria viabilização do empreendimento privado.

A prefeitura divulgava positivamente os resultados do período compreendido entre 1997-2002 apresentando intervenções realizadas, ou em processo, em cerca de 16\% de sua área total, mesmo com empregos gerados de menor qualificação e remuneração, se comparados ao emprego industrial das décadas passadas, nas atividades de serviço e comércio. A base industrial remanescente atualizou tecnologias de produção e gestão aumentando a produtividade. Assim, esta etapa inicial de implantação do PET não é decorrência de sua concepção e sim conseqüência do próprio processo de reestruturação produtiva.

O modelo de implantação urbanística do PET contrapõe-se às suas referências internacionais pois não houve demarcação precisa do território, linhas de crédito subsidiado para intervenções privadas, alterações significativas na legislação urbana ou pesados investimentos em infra-estrutura. Esta contraposição também não representou um modelo alternativo, pois os empreendimentos implantados ou em fase de implantação foram pontuais potencializando as condições de infra-estrutura existentes desde o início do ciclo industrial e apresentando contigüidade física, recursos perenes ou um projeto básico de desenho urbano.

A dinâmica imobiliária dos primeiros anos do PET e a conseqüente geração de recursos em contrapartidas não representava a garantia de continuidade. Nunca existiu um programa específico que acompanhasse o impacto das novas intervenções no entorno imediato ou no município, seja pelo viés do monitoramento dos possíveis impactos gerados no mercado imobiliário ou ainda nas relações de um empreendimento comercial de porte na microeconomia do bairro. Por dificuldades operacionais da prefeitura, o acompanhamento das obras e serviços realizados em áreas públicas era superficialmente realizado. Sua continuidade, caso haja ou não uma mudança de diretriz política municipal, é refém da lógica do mercado imobiliário pois em sua frágil juridicidade não apresentava alternativas de origem de recursos às outorgas onerosas. Seu prosseguimento reafirma e reproduz desigualdades e contradições sociais pois o município não reúne habilidades e competências para subverter a ordem central. Enfim, o PET sintetizou o urbanismo neoliberal travestido de política urbana alternativa. 


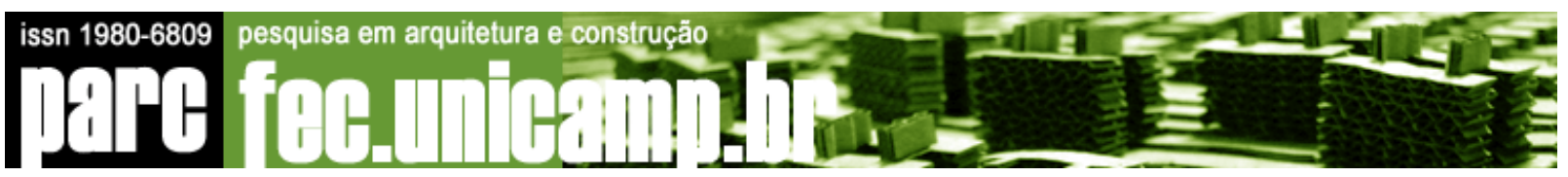

A dinâmica possível de implantação do PET e os resultados iniciais avaliados comprovam que o município brasileiro não reúne competências e habilidades para implementar planos urbanísticos para investimentos públicos e privados que objetivem o desenvolvimento econômico com equidade social e ambiental. O protagonismo municipal presente no PET contrapõe-se ilusoriamente às restrições da expansão do mercado interno, à ascensão de uma burguesia nacional e às condições mínimas de reprodução da força de trabalho, elementos consolidados no processo de reprodução da sociedade brasileira.

Esta contextualização justifica sua fragilidade conceitual na paradoxal relação entre o discurso oficial política urbana alternativa que agregue melhorias nos indicadores sócio-econômicos locais - e o perfil das ações e intervenções realizadas, estas subordinadas tanto às reivindicações da iniciativa privada incorporadas na agenda pública como também à lógica de um mercado limitado às demandas de preservação e aprofundamento da hegemonia da elite nacional.

Outro paradoxo é a desconfortável adoção de princípios urbanísticos que reforçam o neoliberalismo brasileiro travestidos em inócuos discursos que valorizam o voluntarismo municipal na resolução de questões estruturais e conjunturais. Ao município brasileiro, o único arremedo de alternativa ao aprofundamento das diferenças sócio-econômicas no neoliberalismo está restrito à expansão de medidas atenuantes, ineficazes e de grande peso nas finanças municipais, como programas assistencialistas na área de habitação que perpetuam o baixo nível de reprodução da força de trabalho. Esta postura, inexistente redenção, não subverte a ideologia do Estado brasileiro e reafirma a situação extremamente confortável da elite dominante, perpetuando a reprodução da acumulação entravada.

O rebatimento dos conceitos neoliberais no PET é evidente, como o marketing urbano, as possibilidades de venda e vantagens locacionais para o mercado imobiliário, as parcerias público-privadas, a adoção do planejamento estratégico empresarial, a trégua social no contexto cidade-empresa e a subordinação e a intervenção a favor do mercado; suas decorrências no âmbito da acumulação refletem-se na ambígua e fragmentada legislação urbanística municipal, no financiamento limitado e somente viabilizado em locais nos quais a dinâmica imobiliária permite ou nos sofisticados instrumentos e técnicas de gestão urbana que não conseguem propiciar condições de contraposição à lógica da elite nacional, rendendo-se portanto à uma incômoda e velada parcimônia.

A questão de fundo não é o preciosismo na elaboração de um plano urbanístico, prática recorrente de vários municípios, e sim o próprio conflito deste tipo de plano que não 


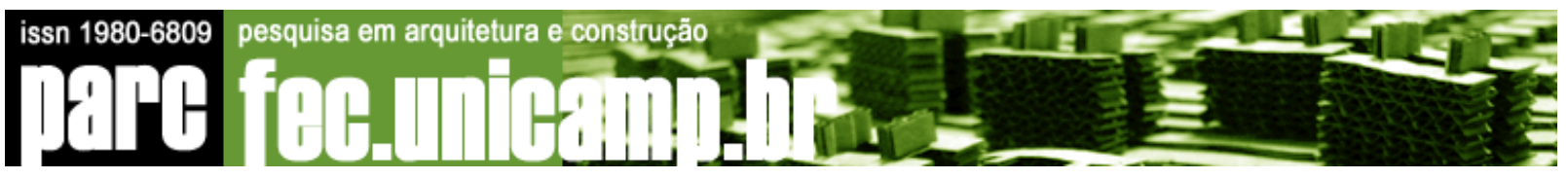

consegue abranger toda a ação necessária para melhorias no território municipal. Reverter esta situação histórica requer romper a acumulação entravada. A incapacidade do município brasileiro em implantar planos urbanísticos com o perfil do PET comprova-se tanto pelo aparato legal disponível à realidade municipal, que frustra pela inoperância e alcance limitado à legalização de irregularidades, como pelo padrão dos recursos utilizados em obras e serviços necessários para sua consecução.

A gestão municipal neoliberal assumiu comportamentos empresariais em relação ao seu desenvolvimento econômico e obtenção de benefícios positivos, referenciando-se em princípios da iniciativa privada. Seu desempenho passou a ser medido por sua capacidade de gerar riquezas e estabelecer competências para a produção de bens e serviços. Valorizou características cenográficas urbanas para atração de novos empreendimentos e ocultou conflitos existentes em seu território.

Tanto em contextos de acumulação entravada ou desimpedida, a lógica de suprir infraestrutura por meio de parcerias só é possível se garantir a lucratividade para a iniciativa privada e a preservação da dominação política. Esta possibilidade, efetiva no Estado burguês, torna-se perversa em um contexto que limita a expansão das forças produtivas e de extrema carência de grande parte da população. Assim, o modelo de parceria entre o público e o privado em uma realidade de acumulação restrita condiciona-se à manutenção da reprodução das relações capitalistas existentes. O papel do município como protagonista de uma possível expansão das forças produtivas pressupõe portanto um processo capitaneado pelo Estado que contemple a ampliação da infra-estrutura, como por exemplo, saneamento, transportes e energia, que não se coaduna com o atual controle fiscal ou ainda com o pacto federativo desigual.

Refletir sobre o alcance dos planos municipais de revitalização urbana como indutores do crescimento econômico e da equidade social significa pensar em um mercado nacional unificado - e o urbanismo é uma de suas faces - que sustente um processo desimpedido de acumulação, a luz de um Estado capaz de intervir na organização da produção e provimento de infra-estrutura. Este contexto de livre desenvolvimento das forças produtivas remete-nos à necessidade de aumento na produtividade do trabalho e no nível de subsistência de sua população. As ações possíveis ao município brasileiro, nas condições atuais, não apresentam densidade política para questionar a reprodução das relações capitalistas no Brasil e suas inferências na produção do espaço. 


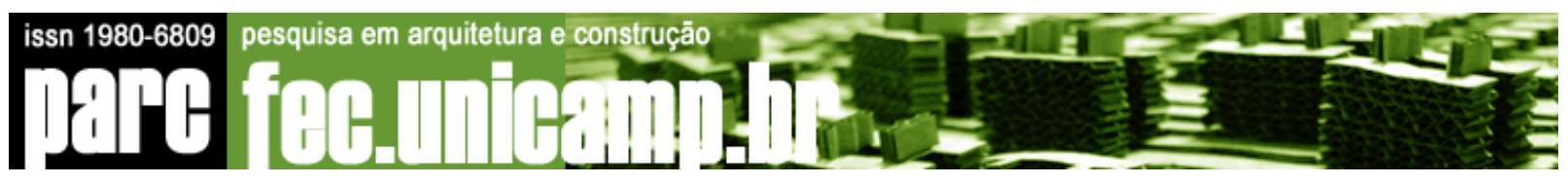

\section{Referências}

ABRUCIO, FERNANDO LUIZ; SOARES, MÁRCIA MIRANDA. Redes federativas no Brasil: cooperação intermunicipal no Grande ABC. São Paulo, fundação Konrad Adenauer, 2002

AGÊNCIA DE DESENVOLVIMENTO ECONÔMICO DO GRANDE ABC. A atividade econômica nos anos 90 no Grande ABC, Cadernos de Pesquisa no. 2. Santo André, SP: 2000.

ANAU, ROBERTO VITAL. As transformações econômicas no Grande ABC de 1980 a 1999. São Paulo, fauusp, dissertação de mestrado, 2001

ARANTES, Otília. Urbanismo em fim de linha. São Paulo, Edusp, 1998;

BATISTA, P.N., O Consenso de Washington. A visão neoliberal dos problemas latinoamericanos. In Caderno no. 6- Dívida Externa. São Paulo, PEDEX, 1994;

BATISTA JUNIOR. P.N., Mitos da globalização. In Coleção Documentos. Série Assuntos Internacionais, 52. São Paulo, IEA-USP: 1997;

BORJA, Jordi; CASTELLS, Manuel. Local y Global. La gestión de las ciudades en la era de la información. Madrid: Taurus, 1997

CANO, W. "Brasil: crise e alternativas ao neoliberalismo" In CANO, W. Reflexões sobre o Brasil e a nova (des)ordem internacional. Campinas, Ed. Unicamp, 1995

DANIEL, CELSO. Poder local no Brasil urbano, in Espaço e Debates no. 24. são Paulo, NERU, 1988

DEÁK, Csaba. The crisis of hundered acumulation in Brazil. BISS 10 - Bartlett International Summer School, Cidade do México, Proceeding BISS 10, London, 1989

À busca das categorias da produção do espaço. São Paulo: Tese de Livre Docência, FAU-USP, 2001.

O mercado e o Estado na organização espacial da produção capitalista, in Espaço e Debates no. 28. São Paulo, NERU, 1989

DEÁK, Csaba; SCHIFFER, Sueli Ramos (orgs.). O processo de Urbanização no Brasil. São Paulo: Edusp, 1999

The Metropolis of an elite society. Mimeo, 2003; 


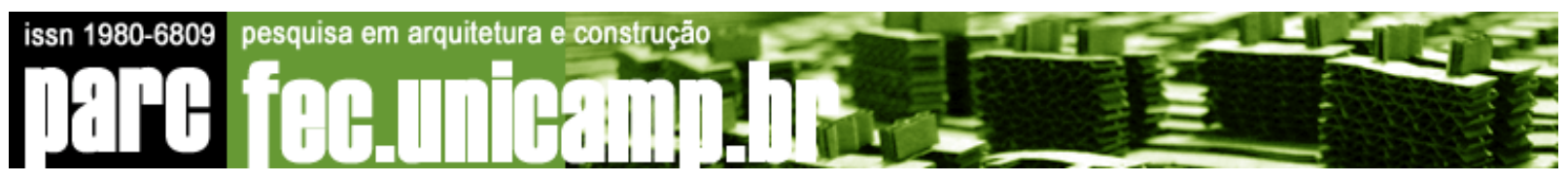

. Relevant actors, formal and informal power structures. São Paulo Metropolitan Region. Mimeo, 2004;

EMPLASA. Sumário de Dados da Grande São Paulo, 1993. São Paulo, EMPLASA: 1994 Plano Metropolitano da grande São Paulo 1994/2010. São Paulo, EMPLASA, 1994.

FIORI, José Luís Os moedeiros falsos. Petrópolis, Vozes, 1997 60 lições dos anos 90: Uma década de neoliberalismo. Rio de Janeiro: Record, 2001

FIX, Mariana. Parceiros da exclusão. São Paulo, Boitempo, 2001;

GORENDER, J. Desafios para uma força social emergente. In Revista Estudos Avançados, 14(39); 7-13, maio/agosto 2000;

GUNN, P. Espaço, estado e Território: contribuição à análise crítica da organização social em São Paulo e no Brasil. São Paulo, Tese de Doutoramento, FAU USP, 1986

- Desmonte industrial como experiência metropolitana: o ABC paulista e o passivo urbano de um mundo automotivo. São Paulo, FAUUSP.

HARVEY, D. A condição pós moderna. São Paulo: Loyola, 1992;

. O trabalho, o capital e o conflito de classes em torno do ambiente construído nas sociedades capitalistas avançadas. Revista Espaço e Debates no. 6. São Paulo: Cortez, 1982

IANNI, O. A globalização ameaçada. In www.pg.cdr.unc.br/Revista Virtual/NumeroUm/Resenha.htm, 22/07/2004;

IBGE. Síntese dos indicadores sociais. Rio de Janeiro, 1999. .www.ibge.gov.br, acesso em 06.mar.2003.

INSTITUTO PÓLIS \& FUNDAÇÃO FRIEDRICH EBERT STIFUNG, 2001, São Paulo: Experiência "Projeto Eixo Tamanduatehy"- Município de Santo André, 2001.

KLINK, J.J. A cidade-região: regionalismo e reestruturação no Grande ABC Paulista / Jeroen Johannes Klink; Giuseppe Cocco (org.). Rio de Janeiro: DP\&A, 2001.

LEITE ARANTES, Paulo Tadeu. Cidades: competitividade, competição e cooperação: estudo 


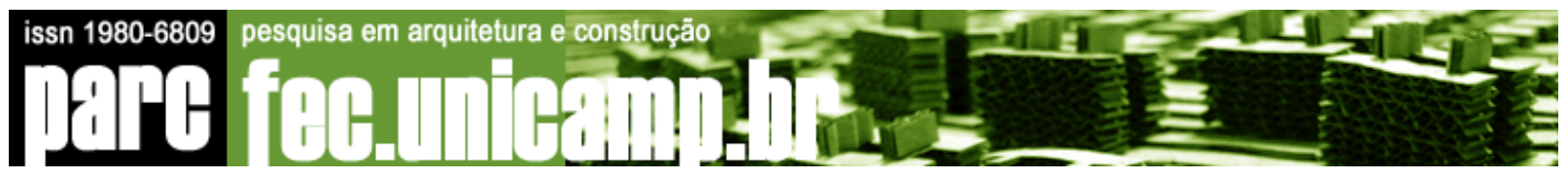

de caso de quatro cidades sulmineiras à luz da competitividade, da competição e da cooperação. Tese de doutoramento, FAU-USP, 2001;

LOPES MEIRELLES, HELY. Direito Administrativo Brasileiro. São Paulo, SP: Malheiros Editores, 2003.

Direito Municipal Brasileiro. São Paulo, SP: Malheiros Editores, 2003

MÉDICI, A . Para entender a formação da Grande São Paulo. Revista Raízes. São Caetano do Sul, 9: 59-62, jul. 1993

MONTHLY REVIEW, The Editors (1992). Globalization to what end? Parts I-II. Monthly Review 43, 1992

MORO JUNIOR, Enio. O alcance dos planos municipais de revitalização urbana: o caso do Projeto Eixo Tamanduatehy 1997/2002. Tese de doutoramento, FAU USP, 2005.

MORPHY, LAURO (ORG). Reforma Tributária em Questão. Brasília, DF: UNB: 2003

OLIVEIRA, A.; DUARTE, L. Modelos de gestão urbana: o caso do município de Santo André. Rio de Janeiro, IPPUR, 2000.

OLIVEIRA, F. Crítica à razão dualista - o ornitorrinco. São Paulo, Boitempo Editorial: 2003;

PIENCASTELLI, M. A guerra fiscal entre os estados brasileiros. In Schiffer, S. Globalização e estrutura urbana. Ed. Hucitec, 2004.

PREFEITURA MUNICIPAL DE SANTO ANDRÉ. O Futuro já chegou. Santo André, SP: 1999 . Sumário de Dados 2001. Santo André, SP: 2001.

REIS Filho. Nestor Goulart. Urbanização e Planejamento no Brasil - 1960/1983. In: Cadernos de Pesquisa do LAP. N. 11. São Paulo: FAU USP, jan. fev., 1996

RIBEIRO, Darcy. O povo brasileiro. São Paulo: Companhia das Letras, 1995

SANTOS, Milton. Metrópole Corporativa e Fragmentada: o caso de São Paulo. São Paulo: Nobel, 1990.

Por uma outra globalização. Rio de Janeiro, Record: 2000

SANTOS, MILTON; SOUZA, MARIA ADÉLIA A. DE SOUZA, SILVEIRA, MARIA LAURA (ORG.). Território: globalização e fragmentação. São Paulo, ed. Hucitec, 1994

SASSEN, Saskia. As cidades na economia mundial. São Paulo: Nobel, 1998 


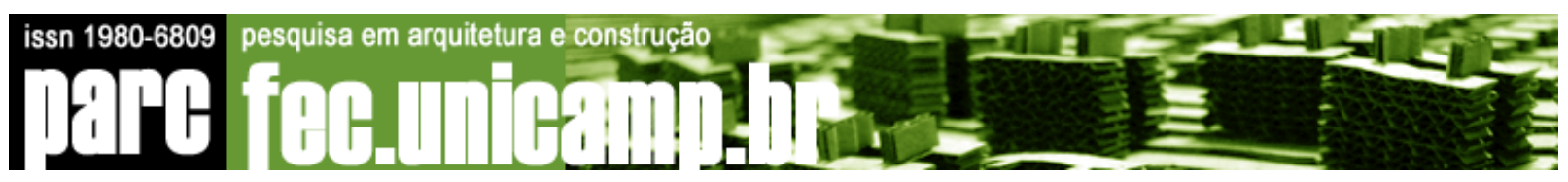

SCHIFFER, Sueli. As políticas nacionais e a transformação do espaço paulista. 1995-1980. Tese de doutoramento, São Paulo: FAU-USP, 1989;

A territorialidade revisitada. Tese de Livre Docência, São Paulo: FAU-USP, 1992. (org.). Globalização e Estrutura Urbana. São Paulo, Hucitec: 2004;

SEADE. www.seade.gov.br, acesso em 30.nov.2003.

SINGER, P. Mercado e cooperação: um caminho para o socialismo In HADDAD (org.). Desorganizando o consenso. Petrópolis, RJ, Vozes: 1998. pp 101-116;

STORPER, MICHAEL. Who Benefits from Industrial Decentralization? Social Power in the Labour market, Income Distribution and Spatial Policy in Brazil. Regional Studies vol 18.2 pp. 143-164 - Mimeo

STORPER, MICHAEL; SCOTT, ALLAIN J. Indústria de alta tecnologia e desenvolvimento regional: uma crítica e reconstrução teórica, in espaço e Debates no. 25. São Paulo, NERU, 1988

THE WORLD BANK. www.worldbank.org/data , acesso em 17.ago.2003.

THUROW, Lester. Cabeça a cabeça. Rio de Janeiro, record: 1998

VIEIRA, J.L. Lei de responsabilidade fiscal e legislação complementar. Bauru, SP: EDIPRO, 2001.

VILLAÇA, Flávio. Espaço Intra-Urbano no Brasil. São Paulo: Studio Nobel, 1998

WILLIAMSON, J., KUCZYNSKI, P. (org). Depois do Consenso de Washington. São Paulo Saraiva: 2004. pp 1-18; 